ISSN 0103-7013

Psicol. Argum., Curitiba, v. 28, n. 61, p. 147-157 abr./jun. 2010 Licenciado sob uma Licença Creative Commons

\title{
ENTRE REAL, SIMBÓLICO E IMAGINÁRIO: Leituras do autismo
}

\author{
Between real, symbolic and imaginary: Readings on the autism
}

\author{
Angela Vorcaro $^{[\mathrm{a}]}$, Ariana Lucero ${ }^{[\mathrm{b}]}$ \\ [a] Psicanalista membro da ALI, professora Dra. do Departamento de Psicologia da Universidade Federal de Minas Gerais (UFMG), \\ Belo Horizonte, MG - Brasil, e-mail: angelavorcaro@uol.com.br \\ [b] Psicanalista, Mestre em Estudos Psicanalíticos pela Psicologia da Universidade Federal de Minas Gerais (UFMG), Belo Horizonte, \\ BM - Brasil, e-mail: luceroariana@yahoo.com.br
}

\section{Resumo}

A partir de afirmações, amiúde reiteradas por psicanalistas na atualidade, que circunscrevem o autismo exclusivamente no Real, coloca-se em discussão a articulação entre os três registros que compõem a realidade psíquica, mostrando a interdependência dos mesmos. Propõe-se a consideração do mecanismo da recusa no autismo como índice de presença, mesmo que restrita, também dos registros Simbólico e Imaginário, à luz de algumas observações depreendidas da obra de Jacques Lacan. Para isso, é indispensável pensar a relação do autista com o Outro e com os objetos que o circundam, de modo a também melhor delimitar uma possível intervenção psicanalítica nesses casos.

Palavras-chave: Autismo. Psicanálise. Real. Lacan, Jacques, 1901-1981.

\begin{abstract}
Based on some assertions, often repeated by psychoanalysts nowadays, that encapsulate the autism in the sphere of the Real, this article discusses the articulation between the three registers of psychic reality, showing the interdependence of these spheres. In light of some observations extracted from the work of Jacques Lacan, it purposes to considerate the mechanism of denial common to autism as an index of the presence, even if it is a restricted one, of the Symbolic and Imaginary realms as well. For that matter, it is necessary to consider the autist's relation with the Other and with the objects that surround him, as a way to better delimit a possible psychoanalytical intervention in these cases.
\end{abstract}

Keywords: Autism. Psychoanalysis. Real. Lacan, Jacques, 1901-1981. 


\section{INTRODUÇÃO}

Desde as importantes formulações feitas pelo casal Rosine e Robert Lefort em meados dos anos 1980, a partir do atendimento clínico de Marie Françoise, temos nos interrogado sobre a dimensão em que o autista opera, pois, segundo esses autores, há um paradoxo apresentado pelo sujeito no autismo, que podemos resumir em poucas palavras como: "O Outro não existe":

Marie Françoise nos confrontou com a ausência do Outro [...] o Outro, se ele não existe, tem, entretanto, presença real de um corpo que faz aí a presença de um Outro absoluto, não barrado, não furado: o significante falta para cortá-lo [...]. Paradoxalmente, não é o Outro que domina, é o Um. [...] nada de especular nem de divisão do sujeito, mas um duplo que $o$ autista reencontra em cada outro, seu semelhante, cujo perigo mais agudo é a iminência de gozo e a necessidade de matar, nele, essa parte que a linguagem não eliminou, para que se funde uma relação com o Outro como terraplenagem higienizada de gozo. [...] Há entretanto uma resposta do autista ao real em que ele encontra sua máscara: fazer o vazio. É a forma mais determinante da abordagem impossível da Coisa (Lefort \& Lefort, 2003, p. 181-183).

Essa passagem leva a outra questão a respeito do autismo que, sistematicamente, assola os psicanalistas, em especial os de orientação lacaniana: "Afinal, o autista está no Real ou ele habita o campo da linguagem, mesmo sem a função da fala?"

Este artigo discutirá essa questão à luz da articulação lacaniana do Real, Simbólico e Imaginário, além de recorrer a outros autores, de modo a tentar melhor delimitar as tão difundidas teses dos Lefort.

Ao tomarmos essa posição, apostamos na presença, mesmo desenodada e precária, dos três registros da realidade psíquica no autismo. Se nos servimos das afirmações de Lacan sobre a distinção radical e o enodamento necessário entre Real, Simbólico e Imaginário, parece no mínimo necessário discutir, nesse contexto, a posição atribuída ao autista.

\section{O Simbólico}

Nas breves observações de Lacan sobre o autismo, o psicanalista sublinha que, ao tapar os ouvidos, a criança está na linguagem, pois dela se defende:

[...] se uma criança que tapa os ouvidos, nos disseram, ao quê? A algo que está sendo dito, não está já no pós-verbal, já que do verbo ela seprotege? No que concerne a uma pretensa construção do espaço que se acredita compreender aí nascente, parece-me antes encontrar o momento que testemunha uma relação já estabelecida com o aqui e o lá, que são estruturas da linguagem (Lacan, [1967] 1992, p. 4, grifos nossos).

Em outro momento, num diálogo em Genebra com o Dr. Cramer, Lacan aponta que o autista é um sujeito verboso:

[...] Como o nome o indica, os autistas escutam a si mesmos. Eles ouvem muitas coisas. Isso leva, normalmente, à alucinação - e a alucinação sempre tem um caráter mais ou menos vocal. Nem todos os autistas escutam vozes, mas eles articulam muitas coisas e trata-se, precisamente, de entender onde escutaram o que articulam. [...] Eles não conseguem escutar o que o Sr. tem para dizer-lhes enquanto se ocupa deles. [...] É muito precisamente [a dificuldade de escutá-los, a linguagem deles como algo fechado] o que faz com que não os escutemos. $\mathrm{O}$ fato de que eles não o escutam. Contudo, enfim, há, certamente, algo a lhes dizer. [...] Trata-se de saber por que há algo no autista, ou no chamado esquizofrênico, que se congela, se pode dizer isso. O senhor, porém, não pode dizer que ele não fala. Que o senhor tenha dificuldades para escutá-los, para dar seu entendimento ao que dizem, não impedem que sejam, finalmente, personagens bastante verbosos (Lacan, [19751] 1998, p. 12-13, grifos nossos).

Efetivamente, se localizamos o sujeito na definição magistral de Lacan de que um significante representa um Sujeito para outro significante, ou seja, $(\mathrm{S} 1 \rightarrow \$ \rightarrow \mathrm{S} 2)$, há sujeito em qualquer concatenação significante. Assim sendo, desde que haja uma demanda e uma resposta, mesmo que essa se reduza à recusa associada a um olhar endereçado por um desvio daquele que o recebe, temos a presença, 
sempre evanescente, do sujeito que concatenou olhar e desvio mesmo que para operar sua descontinuidade.

Por outro lado, se consideramos que esse sujeito evanescente que se remete entre significantes só opera numa rede de articulações a partir das quais ele se faz enunciador, estabelecendo um modo de gestão de seu desejo, talvez seja necessário um circuito bem mais amplo para reconhecer a presença de sujeito, mesmo que para isso seja preciso recorrer a um enunciado não linguístico, como, por exemplo, uma manifestação corporal sistemática de recusa.

Os comentários aqui recolhidos de Lacan se estendem certamente ao que ele mesmo havia desenvolvido desde 1964, relativamente aos operadores lógicos da reunião e da interseção, destacados por permitir deduzir as duas operações constituintes do sujeito, em sua dependência significante ao lugar do Outro (Vorcaro, 1999). Afinal, é do enxame significante produzido no campo do Outro, em que o ser vivo está imerso, que surge o lugar prévio do sujeito como efeito da linguagem. Entretanto, nesse movimento com que é chamado a funcionar, ele pode ser reduzido a esse lugar, funcionando como signo, ou seja, como significante paralisado. Desse modo, o acasalamento de significantes primeiramente localiza o representante representativo do sujeito, na medida em que o primeiro significante surge no campo do Outro e representa o sujeito para um outro significante do arsenal do Outro.

Entre o ser e o sentido induzido pela função significante, o sujeito subsiste decepado dessa parte de não-senso do ser. Essa forma lógica da reunião define a operação de alienação, cujo resto, a separação, encontra a via que reverte a alienação: o sujeito encontra o ponto fraco do casal primitivo da articulação significante em que é localizado. Operando uma torção essencial, o sujeito encontra, no intervalo entre esses dois significantes, um ponto de falta em que o próprio desejo do agente do Outro está para além ou para aquém do que ele faz surgir como sentido, ao invocar o sujeito.

A concatenação significante implica descontinuidades que lhe são próprias por estrutura. Ao encontrar uma falta no Outro, na intimação que o agente do Outro, por seu discurso, lhe faz, o sujeito apreende o desejo enigmático do Outro. Para responder a isso, o sujeito traz a falta antecedente do próprio desaparecimento de seu ser, que ele vem agora situar no ponto da falta do Outro. Portanto, desde que esteja concernido pelo campo da linguagem, o primeiro objeto que propõe a esse desejo materno, cujo objeto é desconhecido, é sua própria perda, ou seja, antes de qualquer determinação desse objeto e desse desejo, surge na experiência da criança: isso me concerne, mas o que isso quer? Isso pode me perder? A fantasia de seu desaparecimento é o primeiro objeto que o sujeito tem a pôr em jogo nessa dialética. Uma falta recobre a outra, numa dialética que faz a junção do desejo do sujeito com o desejo do Outro. É uma falta engendrada pelo tempo precedente que serve para responder à falta suscitada pelo tempo seguinte.

Separado de seu lugar prévio - a cadeia significante -, o sujeito deixa de estar ligado apenas ao sentido que constitui o essencial da alienação. Nesse campo, o que faz função é o objeto $a$, elemento não significante que tampona o intervalo significante, objeto atravessado entre os significantes. Nesse ponto de falta, o sujeito, efeito do significante, articula-se ao elemento não significante. Aí o sujeito representa sua parte e joga sua partida na separação, engendrando-se, pondo-se no funcionamento da linguagem, recobrindo duas faltas na forma lógica da interseção dos elementos comuns ao sujeito e ao Outro: a falta no Outro, aquilo que é impossível à linguagem, ou seja, o desejo, presença de algo que falta na articulação significante, que a fala não pode capturar, e a falta do sujeito que foi amputado de seu ser pelo sentido que lhe foi dado.

Nos diferentes modos de se fazer com a linguagem é necessário que a criança constate que esse desejo indeterminado da linguagem lhe diz respeito. As recusas ou fracassos nos forçam a considerar o modo pelo qual o sujeito, como efeito da linguagem e da fala, está ligado ao gozo (Soler, 1997, p. 63-64). A estruturação do infans em falante implica mudar algo na substância de gozo do ser operando com a linguagem. Se operações de alienação e de separação permitem-nos supor que a recusa do autismo tem estatuto de resposta ao modo pelo qual o infans foi conduzido pelo Outro a situar-se numa posição, essa resposta implica solidificação da linguagem: "quando não há intervalo entre $S_{1}$ e $S_{2}$, a primeira dupla de significantes se solidifica, se holofraseia" (Lacan, [1964] 1988, p. 225) ${ }^{1}$. Todavia, a intrusão da

\footnotetext{
1 A consideração de uma língua inteiramente holofraseada interrompe o uso da noção de holófrase. Para J.-A. Miller, depois do Seminário XI, o novo nome da holófrase é Um, S 1 sozinho. Laurent, 1991, p. 132.
} 
linguagem no ser fez marca, impregnando-o, sem que, com ela, ele pudesse brincar. Ilegível por não estar concatenado a suas bordas, o traço que inscreveria o sujeito está desarrimado de uma série significante qualquer, pois a criança não os conta, não os substitui nem os ordena.

A solidificação do primeiro casal de significantes impede que um significante possa vir no lugar de outro, num só tempo discretizados e concatenados. O sujeito não aparece como falta, mas como monolito cuja significação se iguala à mensagem enunciada.

\section{O Imaginário}

Ao se perguntar sobre o parâmetro sob o qual seria possível, ao mesmo tempo, distinguir, homogeneizar e ordenar Real, Simbólico e Imaginário $^{2}$, Lacan aponta o embaraço causado quando temos que localizar a medida comum a partir da palavra "outro". Afirmando que Freud, lamentavelmente, se confundiu aí, ao considerar "outro" a partir do que é interior/exterior, Lacan lembra que há outro "outro", escrito com "O" maiúsculo, que não tem a mínima relação com o interior/exterior. Essa questão remonta ao Seminário 16 ([1968-1969] 2008, p. 271-285), no qual ele aponta que a concepção de representação proposta no idealismo conduz ao equívoco de estabelecer a separação entre real (o fora) e representação (o dentro) nos moldes do que a ótica permite com a câmara escura. O psicanalista propõe a interrogação rigorosa dos termos dentro e fora presentes desde a origem no pensamento de Freud. Sigamos seu raciocínio.

Quando consideramos o organismo, o indivíduo, pode parecer evidente estabelecer um dentro e um fora. O dentro seria aquilo que está no interior de seu envoltório da pele. O fora seria todo o resto. Pensar que o que ele representa para si desse fora, a sua imaginação, também deve estar no interior do envoltório da pele, parece, à primeira vista, ser evidente. Para Lacan, a construção dessa representação de miragem é fundamentada na ótica, em que o modelo da câmara escura localiza a função do sujeito, apoiando a ideia de que o psiquismo seria situado num dentro limitado por uma superfície. Apenas ao sair da fascinação de só conceber a representação no interior do corpo, poderemos analisar o que acontece no dentro e no fora.

Dessa maneira, para pensar a relação entre o sujeito da sensação e o mundo do sentido, Lacan propõe que consideremos aquilo que falta atrás da imagem, a mancha que se distingue como furo, como uma ausência estruturante a título de lugar de falta, no lugar do terceiro termo do campo objetivado.

O psicanalista situa nas ausências estruturantes demarcadas pelo objeto a o princípio do que liga o mundo do sentido a um sujeito cujo saber é totalmente dominado por uma outra falta mais essencial, que lhe diz respeito como ser sexuado. Todas as relações que retêm o ser falante encontram sua raiz na mancha que tampona e supre a falta, graças à qual o ser falante pode situar-se em relação à sua pertença sexual.

De acordo com Lacan, Freud se situa nesse nível quando comprova que o pensamento é, por si só, censura. O pensamento tampona e supre uma falta; ele é censura que costura esse furo. Lacan nos lembra que o pensamento é concatenação significante e só é concebível ao ser articulado, ao se inscrever na linguagem. Não sabemos o que é um pensamento quando ele é guardado. A essência do pensamento está do lado de fora. Mas esse fora não é um espaço aberto para o infinito, no qual colocamos seja o que for sob o nome de real. Lacan é categórico ao afirmar que aquilo com que lidamos nesse fora é o Outro, marcado por uma falha.

Os organismos que subsistem apenas no real nos obrigam a conceber que a relação de que eles se servem para subsistir é Imaginária. Algo indica ao organismo que um dado elemento do exterior, do meio, do Umwelt, é absorvível por ele, ou seja, é propício à sua preservação. Isso significa que o Umwelt é uma espécie de duplo do organismo. Toda a ordem do Umwelt é descritível em termos de adequação, para a subsistência do indivíduo. Diferentemente do organismo, o ser falante subsiste com a ordem simbólica. Mas a ordem simbólica não é apenas uma lei, diz Lacan, é também uma acumulação numerada. É uma ordenação. Por isso, qualquer evocação da falta supõe instituída a ordem simbólica. Isso quer dizer que para a aparição da existência da falta, ou seja, para que falte alguma coisa, é preciso que haja uma contagem. Só a partir do momento em que há

2 Lacan, Lição de 10 dez. 1974. 
contagem, há efeitos da contagem (S) na ordem da imagem (I).

A partir desse esclarecimento de Lacan, podemos formular algo do funcionamento do autismo. Ou seja, podemos conceber que o autista sofre os efeitos do campo da linguagem, ao ceder ao imperativo da lei da linguagem sem falecer (e sem falasser), porque subsiste estabelecendo com os elementos que ele discretiza do real, uma relação privilegiadamente Imaginária. Alguns elementos do meio, do Umwelt, são absorvíveis por ele, fazendo do Umwelt uma espécie de seu duplo, algo adequado a ele, na correspondência biunívoca em que o Umwelt lhe confere seu peso, seu sentido, seu alto e seu baixo, sua direita e sua esquerda. Assim, a ordenação mínima que ele estabelece (servindo-se da lei da linguagem) é unívoca (entre ele mesmo e o elemento que ele retira do real) ou binária (entre dois elementos do real) mas não ultrapassa essa contagem, resistindo à ordenação, à concatenação das imagens que assim se complexificariam pela contagem que lhe faria supor o Zero como eixo da escala.

Esse funcionamento reprodutivo da relação macrocosmo/microcosmo deve-se ao fato de o registro do Imaginário ser formado por um enquadramento de uma referência integral à imagem do corpo. E os registros do simbólico devem encontrar seus suportes na função imaginária, diz Lacan.

No Seminário 22, Lacan lembra que o Imaginário tem como ponto de partida a referência ao corpo. Mas, para atestar que um corpo esteja vivo, erogeneizado, é necessária sua debilidade mental, que se introduz com a alíngua, ou seja, um saber que ex-siste, que enquista sem que se saiba em que consiste. Nessa perspectiva está a riqueza do termo intelleggere, ler entre linhas, que aponta para o que se diferencia do simbólico. Ler entre linhas é ler diferente de como o Simbólico escreve, sendo, entretanto, um efeito de escritura do Simbólico em que se guarda o efeito de sentido. Só a linguagem permite localizar a debilidade que o corpo suporta, testemunhando ser vivo.

Assim, podemos dizer que, sem estabelecer a contagem, ou seja, sem desdobrar e armar suficientemente o registro simbólico, o autista não pode se servir da função imaginária para potencializá-lo. Restringindo-se às primeiras operações que se limitam à biunivocidade, dissolve qualquer perspectiva das propriedades e consequências da articulação gramatical.
Com Lacan ([1968-1969] 2008, p. $257-$ 270), podemos considerar que apenas a contagem permitirá estabelecer listas, ordens, correlações e funções em que o saber se conjuga, além de poder situar um saber falho, o trauma enquanto um Eu não sei impensável, que supõe um Eu penso desvinculado de qualquer pensamento.

Esse ponto de origem estrutural do inconsciente, do qual nasce o desejo de saber, está vedado ao autista. Antes da contagem não há nada a dizer desse lugar, pois ele é criado por um isso não quer dizer nada. E é o "isso não quer dizer nada" enquistado na ordenação simbólica que exige um "isso quer dizer" substituto. A falha criadora do saber e ponto-origem do desejo de saber faz do saber o correlato dessa falha.

\section{O Real}

A incidência da ordem significante é traçada a partir do investimento fálico da alteridade na criança, na dialética instaurada a partir da função imaginária do falo, promotora da operação metafórica do Nome-do-pai que permite ao sujeito evocar a significação do falo. Entretanto, só depois que a simbolização lhe indica o lugar, o sujeito seinscreve no simbólico, "carregando o verso da causa que o fende" (Lacan, 1966). Entre a experiência da atribuição fálica e a sua significação temos, portanto, um lapso a ser percorrido não apenas enquanto contingência temporal, como também enquanto formação do inconsciente, na estrutura temporal reversiva em que a castração retroage ao recalcamento originário para lhe conferir significância (Vorcaro, 1997). Recorrer ao enodamento do Real, Simbólico e Imaginário permite-nos escrever as condições de gozo e contar os seus resíduos. Cada uma das intersecções entre os círculos R, S, I notam as ramificações do gozo, por falta do gozo pleno que não há:

A realidade é abordada com os aparelhos do gozo. [...] aparelho, não há outro senão a linguagem. É assim que, no ser falante, o gozo é aparelhado. [...] Isto quer dizer que o gozo é anterior à realidade (Lacan, [1969-1970] 1992, p. 75).

Circunscrito na interseção do Real com o Imaginário, o gozo do Outro refere-se ao gozo para além do falo, gozo imaginado pelo sujeito como 
pertencente ao Outro, posto que nada confere aval ao gozo do corpo do Outro. Um solitário que se conta sem ser, que não se soma a nenhum Outro numa relação de pleno gozo. É o que implica, para Lacan, que a função do Outro seja situada como uma diferença que participa do Um sem adicioná-lo a si, ou seja, o Outro é o Um-a-menos. É a impossibilidade real do gozo fálico que é suposta pelo sujeito como parasita, ao fazer prevalecer o obstáculo em que ele privilegia uma referência de gozo como pertencente ao Outro: "ao se marcar de que distância ele [o gozo] falta, aquele de que se trataria se fosse isso, ele não somente supõe aquele que seria isso, ele suporta supor, comisso, um outro" (Lacan, [1973-1974] 1982, p. 152).

O gozo do Outro se situa alhures, está fora do corpo e lhe é anômalo: "O Outro do Outro real, isto é, impossível, é a idéia que temos do artifício, visto que ele é um fazer que nos escapa, isto é, que transborda em muito o gozo que podemos ter dele" (Lacan, [1975-1976] 2007, p. 62).

Se a incidência da indeterminação (real) de um gozo invade imaginariamente o sujeito reduzindoo a ser seu objeto que causa a angústia, o autista se antecipa a ela defendendo-se por meio da recusa. Diferentemente da fobia, sua recusa seria, portanto, a sentinela avançada contra a angústia. Mas essa perspectiva implica considerar não apenas o Real no autismo, mas, como vimos, alguma incidência da linguagem e, mais ainda, a presença do imaginário, em seu caráter de antecipação, de precaução e de duplicação, pela qual ele inventa um atamento das três dimensões, mesmo que aquele escape à condição borromeana da estrutura.

Contando com esses elementos, podemos voltar ao Seminário 10 ([1962-1963] 2005) para localizar a posição do autista como um impasse situado a partir da função da primeira incidência da angústia na estruturação do sujeito. Lacan nos lembra que, entre o sujeito do gozo e o sujeito do desejo, a angústia localiza o tempo de impasse que só se ultrapassa quando produz um resto inassimilável ao significante, permitindo a travessia. O usufruto do gozo (enxame significante) é reduzido pela linguagem (localizando um $S_{1}$ pelo $S_{2}$ ), mas não sem manter nela um objeto que o recupere. Por isso, podemos dizer que "o gozo não conhece o Outro senão através desse resto, a" (Lacan, [1962-1963] 2005, p. 192).

Esse dejeto, $a$, que não pode assumir função substitutiva do sujeito do gozo, é, entretanto, o que mobiliza o ser a assimilar o Outro. Nessa dialética de engajamento do vivente no significante mantém-se, no corpo, algo de separado (Lacan, [1962-1963] 2005, p. 242). Resíduo de gozo sobrevivente do encontro com o significante, sua função será a de sustentar e mobilizar o desejo, mesmo que esse seja ilusório porque não se dirige a seu alvo suposto, mas sim ao resto constituído pela relação do sujeito com o Outro (Lacan, [1962-1963] 2005, p. 262). É o que nos permite distinguir "objeto do desejo" de "objeto causa de desejo".

É necessário que a criança localize o campo do Outro no agente de seus cuidados, para que possa localizar a presença de uma demanda, ou seja, uma falta que irá superpor a sua própria falta. Essa figuração primeira do Outro que forclui o gozo transmitindo a linguagem, também transmite que a linguagem é furada, é desejante, pois só é viva quando se dá uma mãozinha para ela, como diz Lacan no Seminário 22.

Identificar sua própria falta a essa falta constatada no Outro é a primeira rota da constituição de um lugar desde o qual possa responder, na linguagem. Isso, o autista não faz. Podemos supor que a rota se paralisa, no autista, na recusa em se oferecer ao agente do Outro.

A recusa radical do autista é à posição de alvo do gozo de uma potência imaginarizada como Real. Ao retrair-se, declinando seu corpo da posse dessa potência, intercepta o laço pulsional que o ligaria ao Outro, neutraliza a procura de satisfação no Outro, obstaculizando a erogeneidade pulsional com a qual faria laço, mas, mantendo-se à margem, livra-se de ser aniquilado, como objeto do gozo do Outro. Por isso, a organização defensiva do autista seria um trabalho para fazer frente ao Outro. Di Ciaccia (2005, p. 34-35) defende que, em vez de se fazer representar e se fazer barrar pelo significante como os demais, o autista não está barrado e, desse modo, encarna no real a presença do objeto fantasmático que preenche a falta do Outro. Por isso não tem êxito na circulação do discurso. Dessa perspectiva, o objeto da criança autista não é para brincar, mas é algo que a completa e ao mesmo tempo algo que a isola. Esse elemento não é um meio em direção ao outro, e sim um complemento que mantém a homeostase, uma proteção e uma barreira. Assim, a circularidade primária que existe entre significante e gozo se realiza. No entanto, para Di Ciaccia, o significante se apresenta para o autista não em sua face simbólica, mas em sua face real. 
Pelo que analisamos anteriormente sobre a relação entre $\mathrm{R}, \mathrm{S}, \mathrm{I}$, seria necessário considerar, diferentemente de Di Ciaccia, que o significante se apresenta para o autista em sua face imaginária. Entretanto, o fato de não haver constituído a ordenação simbólica faz com que a consistência desse imaginário seja restrita a duas únicas possibilidades: algo a ser assimilado como duplo que the corresponde, ou algo que ameaça desintegrá-la.

Voltando a Di Ciaccia (2005, p. 35), devemos ressaltar que a fala do autista perde seu valor de comunicação para revelar a estrutura do gozo. Em vez de afastar o sujeito do gozo, pela conexão ao Outro, a fala é o meio pelo qual o autista se confronta com o gozo mortífero, em excesso, sem regras. A fala serve para gozar e não para dizer. Por isso defende-se tanto dela quanto do gozo sem regras que retorna no real de seu corpo, sem a indução do Nome-do-pai que separa dizer e gozar.

Podemos, entretanto, dizer que sua fala que lhe retorna intrusivamente não se define por ser real, mas por ser uma imaginarização da ameaça de desintegração. Sem participar desse equívoco pelo qual os falantes se distraem, o autista não se engana. Para ele, existe o Um sozinho sem o Outro, que se manifesta pelo gozo (Di Ciaccia, 2005, p. 35-36). Ou seja, como vimos, a impossibilidade de concatenação simbólica dos uns imaginários diferenciados the impede complexificar a articulação simbólico-imaginária, localizando e hipotetizando faltas que permitiriam poder apoiar o funcionamento simbólico.

Di Ciaccia afirma que a criança autista trabalha para defender-se do Um-sozinho. A fala a ela dirigida toma valor de gozo traumático congelando a criança, porque o simbólico toma valor de real. A autodefesa do autista anula o que pertence ao registro do Outro que poderia ser assimilado ao Um-sozinho, em razão da ausência de separação. Instaurar um mínimo de vida implica em tentativas do autista, com seus próprios recursos, fazer um mundo regido pela estrutura elementar do simbólico, provando que o simbólico é o pai do homem. Esse ajuste simbólico mínimo se introduz por certos movimentos que o autista faz, valendo-se de objetos (aí incluído o corpo). Tenta construir o mais e o menos, o ir e o vir, o abrir e o fechar, sempre numa batida em dois tempos a qual se aplica de forma automática. Assim, um apêndice qualquer que funcionalmente é parte do corpo - muco ou saliva por exemplo - produzem uma ínfima organização de gozo. Entretanto, o meio da operação não é o significante que se serve do corpo depois de tê-lo anulado, mas o próprio corpo ou um objeto que se junta ao corpo e que o complementa, regulando-se por certas propriedades, como uma alternância binária. Neles podemos reconhecer a ordem significante, porém o observador a toma como uma estereotipia. A anulação do Outro é paga com a não anulação do objeto, não elevado ao estatuto significante. A alternância impressa nos objetos se congela de modo que o Outro não entra simbolicamente em jogo. O objeto não cai e sua repetição não se articula como um encadeamento significante, permanecendo na ordem do gozo (Di Ciaccia, 2005, p. 36-37).

Assim, Di Ciaccia considera que, ao contrário do neurótico, em que, inicialmente, o simbólico freia o gozo, o autista recebe primeiro o simbólico como real, e só depois consegue vê-lo como uma barreira ao gozo, mesmo que se defenda dele. O apaziguamento que o autista consegue nesse trabalho não suporta qualquer alteração ou surpresa. Para Di Ciaccia, o autista faz o real com o simbólico e o imaginário. Enquanto em outras psicoses o imaginário pode oferecer a função de suprir o simbólico como um ponto de enganchamento sólido e operativo para sua sobrevivência, o autista não pode contar com o imaginário (Di Ciaccia, 2005, p. 37-38).

Entretanto, talvez possamos dizer que, no autista, o simbólico, em sua redução a elementos soltos, sem ordenação e encadeamento, só pode vigorar como imaginário. A biunivocidade aí, longe de reproduzir uma estrutura simbólica mínima, apenas relança a mesma função imaginária em que o Umwelt é o duplo do organismo.

Di Ciaccia refere-se a esclarecimentos de Miller para introduzir elementos interessantes sobre as duas valências do simbólico, lugar e posição, considerando-as disjuntas no autismo.

Como outras crianças, o autista recorreria ao simbólico como lugar. $\mathrm{O}$ autista também estaria no lugar do Outro, lugar do inconsciente, cena em que se joga a partida de seu destino. Ele estaria numa rede simbólica que segue a lógica encontrada na passagem de uma geração a outra. Todavia, nessa lógica, o autista não estaria representado por um elemento - o significante-que o representa em uma série que torne seu destino contingente e permita a ela possibilidades inéditas. No autista, o lugar do 
inconsciente é fixo, congelado em um destino previamente traçado. Ele ocuparia lugar numa espera perene chamando o significante, na sua batida repetitiva, colocando-o em jogo em seus objetos, seu próprio corpo ou no apêndice que a complementa, tentando inscrever o significante sem sucesso. O lugar, ou seja, o enquadramento simbólico que permite certo apaziguamento ao autista, o mantém protegido do real, dos caprichos do Outro.

Contudo, o autista não buscaria o simbólico como posição. Sem substituição, sem metáfora, sem deslocamento, não há separação entre lugar e posição e, sem essa separação, o simbólico não adquire valor de real: recalque, denegação, forclusão do Nome-do-pai. Sem posição, o simbólico não pacifica nem estabelece laço social, vai à deriva sem orientar-se pelo desejo do Outro (Di Ciaccia, 2005, p. 39). Assim, o Outro da fala (do reconhecimento e da dádiva concedida ao sujeito) é inoperante, não pacifica o Outro da linguagem (que submete o ser humano ao reino da mortificação), não é recoberto pelo Outro da fala ${ }^{3}$. Por isso, a fala dirigida à criança adquire valor real (Di Ciaccia, 2005, p. 40).

Talvez possamos reconsiderar essa afirmação com a hipótese de que é insuportável ao autista constatar que há falta porque, para ele, havendo falta só lhe resta aderir-se a ela, preenchê-la. Quando um outro fala ao autista, demonstra-lhe a falha no simbólico, pois, necessariamente, uma demanda esboça-se. Esse real da linguagem é imaginarizado por ele como risco de sua própria absorção. Só lhe interessa, portanto, o Outro consistente e estável, o que só é possível quando o Outro se reduz a um objeto com função sígnica e a uma ordem restrita o suficiente para retornar sempre ao mesmo lugar. $\mathrm{O}$ autista não pode dar uma mãozinha ao código assim construído porque o vazio das frestas do simbólico não foram substituídas por objetos $a$. Os olhos (e os outros lugares de borda do objeto a) do autista são integralmente passíveis de substituição pelo seu próprio corpo. Os objetos que cria isolam e amortecem o risco dessa dissolução. A colagem biunívoca ao signo, faz com que o autista reconheça, em qualquer pressentimento de falta, o lugar de sua captura. Não é à toa que ele vigia esse risco de ser sugado.

\section{O Outro}

A pergunta sobre o que qualifica o Outro no autismo aponta que algo do autista não cessa de não se escrever. Talvez, salientar esse retorno sistemático permita demarcar melhor o traço do autismo que não se escreve. Mas, talvez, seja antes necessário retomar o primeiro plano de nossas dificuldades quando debatemos a clínica do autismo: a observação.

Demarcamos, com Lacan, que essas crianças são sujeitos na medida em que falamos com elas. A suposição de sujeito por meio dos significantes do Outro é a primeira emergência de qualquer sujeito, já que assim ele está representado por significantes no campo do Outro. Entretanto, esbarramos no fato de que essa primeira emergência do sujeito como puro efeito do Outro não ultrapassa esse limiar para tornarse um agente que fala, movido pela pulsão (Soler, 1997). Abordamos os autistas sem testemunhar a presença de um agente que fala, e ficamos limitados a teorizar ou a interpretar comportamentos: "É como se-estamos, é claro, no 'como se', somos realmente obrigados a interpretar comportamentos" (Soler, 1997, p. 70); ou ainda: “O autista está na linguagem que aí está enquanto alucinada. Nós não o sabemos unicamente porque ele não pode testemunhá-lo" (Zuliani, 2008, p. 113).

Efetivamente, a condição de estrutura e das modalidades de amarração e de desamarração do Real, do Simbólico e do Imaginário, impõe particularidades às condições que tornam possível essa interpretação de comportamentos sem, entretanto, assumirem o estatuto de transliteração necessária à teorização. Se no autismo apenas interpretamos comportamentos ou se o autista não pode testemunhar a linguagem alucinada, nossas observações implicarão nosso imaginário. Sem a circulação pela fala no campo da linguagem, não há como ler as cifras da criança sem contar com a modalidade pela qual o clínico enoda Real, Simbólico e Imaginário ao operar um dizer que franqueie à criança a leitura de suas marcas, para desarrimar o gozo aderido a elas.

Portanto, é necessário problematizar o limite de nossas observações clínicas relativas aos autistas e melhor precisar o uso que fazemos de nossos

\footnotetext{
3 “Outro da fala" e "Outro da linguagem" são termos tomados de Miller por Di Ciaccia em "Lacan contra Lacan”, In Lacan et al. (1986). Il mito indivuduale del nevrotico (pp. 94). Roma: Astrolábio.
} 
operadores teóricos. A constrição da função da fala nessas crianças e nossa dependência da observação de seus comportamentos pode nos impactar a ponto de também restringir nossos recursos simbólicos. Assim, encontramos dificuldades em interrogar a teoria, demarcando o efeito de real que a clínica do autismo pode nos causar. O lugar atribuído ao autista pelo Outro (aí incluídas nossas afirmações) pode fazer com que tomemos como homogêneos o campo da linguagem e o espaço, para nós, indiscernível, em que o autista estaria mergulhado. A observação de Lacan em 1967 dá conta de tal dificuldade. Ele lembra que, ao tapar os ouvidos, a criança oferece o testemunho "de uma relação já estabelecida com o aqui e o lá, que são estruturas da linguagem".

Podendo distinguir e mesmo privilegiar enunciados do campo da linguagem, mesmo que por oposição ou recusa, a criança autista não profere uma enunciação pela qual - sincronicamente - se aliena e se destaca da rede significante. Por isso, circunscrevendo o Outro como o lugar da dialética da linguagem, os Lefort (2003, p. 181) afirmam que no autista o Outro está ausente. No entanto, podemos considerar que, se a dialética está ausente, como atesta o limite de sua enunciação, há modalidades, específicas no autismo, de afetamento pela linguagem, mesmo que essa não contemple sua função plena. Por isso, talvez, ao afirmar que o autismo detém-se na borda da alienação, Soler ([1997] 2007, p. 63) julgue necessário esclarecer que não crê na existência de um autismo puro.

Laurent (1997), ao analisar o autismo considerando a bússola lacaniana do $\mathrm{S}_{1}, \mathrm{~S}_{2}$, a e $\$$, sugere considerar o autismo uma esquizofrenia. Enquanto a tentativa da paranoia que responsabiliza o Outro pelo retorno do gozo, a esquizofrenia se distingue pela tentativa de juntar um órgão ao seu próprio corpo. Nessa hipótese, ele considera uma formulação de Lacan que toma a linguagem como órgão que ex-siste, cuja função determina o humano. $\mathrm{O}$ dito esquizofrênico, tal como o autista, se sustém desse órgão que lhe cria problema, pois jamais a linguagem pôde neles fazer órgão.

Laurent (1997, p. 41-42) avalia haver a passagem direta do significante $\left(\mathrm{S}_{1}\right)$ no real. Isso seria sensível no modo como os autistas se deslocam por um espaço de gozo não métrico onde o infinito e o ao lado são o mesmo porque a escala mestre, o falo, não está presente. Sem significação fálica o mundo não é mensurável. Por isso, o Outro pode sempre invadir o autista com um gozo atroz. No autismo, a posição do saber na língua, o outro significante $\mathrm{S}_{2}$ se encontra em oposição direta, radical e em pura exterioridade.

Quando nos perguntamos, ainda hoje, sobre o Outro do autista, evidenciamos a deriva insistente pela qual podemos supor faltar uma unidade de medida a partir da qual possamos avançar. Ao tentar sistematizar nossas constatações clínicas sobre os autistas, podemos ficar, por vezes, impregnados pelos próprios efeitos da experiência clínica que nos remete ao limbo entre o vivo e o sujeito. Talvez por isso, o efeito de Real que o autista pode produzir sobre o clínico franqueie a esse a especularização de sua própria experiência, situando-a como sendo aquela do autista. Afinal, que o autista faça presente o nonsense do real, para aquele que circula no simbólico, não é difícil constatar. Como dizem os Lefort (2003, p. 181), o autista nos confronta com a ausência de Outro. Contudo, parece excessivo afirmar que o autista está no Real, desprovido de Simbólico e de Imaginário, quando só constatamos que o autista causa, ao clínico, a angústia do encontro com o Real.

Consideramos extremamente aguçadas as observações dos Lefort sobre o autismo que, efetivamente, fomentaraminúmeros trabalhos e, porisso mesmo, julgamos pertinente retomá-los para melhor circunscrevê-los. Por exemplo, a afirmação de que no autismo a criança faria oposição, com seu ser, ao Outro real que ela duplicaria, se colocando como o espelho no real (Lefort, 1997), poderia ser articulada na topologia lacaniana? A distinção e o limite entre as dimensões Real, Simbólico e Imaginário permitem articular os termos "Outro Real duplicado"? Ou seja, o Real (que não se escreve) pode qualificar o Simbólico (Outro) por meio do Imaginário (duplicar)? Se espelhar implica algo do funcionamento imaginário, espelho no real seria expressão possível?

Acreditamos ter fornecido elementos suficientes para repensar, não só essas, como muitas outras questões sobre o autismo. Zuliani (2008, p. 113-114) propõe duas vias para a abordagem do autismo:

1. "há então Outro no autismo, mas tratase de saber de qual Outro se trata" (ou "como o autista trata seu Outro");

2. a "pesquisa sobre a questão dos objetos autísticos", que coloca a questão do "tratamento do ser que não passa pelo 
uso de significantes". Tendo abordado a primeira via, passemos ao exame da segunda.

\section{O objeto}

O trabalho de Maleval (1997) nos diz da função de defesa de certos objetos que, ao se colarem a certos significantes, produzem um efeito de animação com estatuto de máquinas. Essa máquina seria uma realização do simbólico, por ser um objeto portador de significantes organizados.

O objeto autístico bruto ainda não tem significantes organizados, mas já é utilizado pelo sujeito para colocar ordem no mundo, quando ele o faz participar do trabalho de manutenção da imutabilidade e para proteger-se do desejo do Outro.

O objeto autístico não regulado torna-se portador de significantes ordenando o mundo de modo mais elaborado. O sujeito se cola ao objeto numa relação transitivista ou em um estado de inércia.

O objeto regulado implica o uso de significantes em que o autista-sábio se encontra tomado em massa, como testemunham os que respondem quase alucinatoriamente sem trabalho voluntário a perguntas colocadas para testar suas habilidades extraordinárias.

O objeto regulador, por sua vez, é uma defesa mais altamente elaborada. O sujeito pode se desligar dele, mas mantém sua referência fixada pelo significante. Ele instaura uma distância que permite ao sujeito desenvolver adaptações a situações imprevisíveis.

A consideração de que o Outro com que o autista-sábio faz par não é barrado, não tem divisão subjetiva, mas é organizado, leva Maleval a recorrer a uma definição de P. Bruno: trata-se do "Outro de síntese", em que autistas adultos constroem apoiando-se sobre um objeto que instaura uma borda entre o sujeito e o Outro do desejo. Holofraseado, reservatório do objeto real, permite estruturar a realidade e preservar o desejo do Outro.

Enquanto o $\mathrm{S}_{1}$ permite normalmente assegurar a unidade da copulação do sujeito com o saber representando o sujeito em uma posição de exterioridade envelopante que permite o ordenamento da cadeia, como disse Lacan no Seminário 20, o autista-sábio produz alguns aglomerados de $\mathrm{S}_{1}$ ordenados: listas telefônicas, calendários, horários de trens, etc., dos quais não se destaca nenhuma enunciação. Sem referência fora deles mesmos, esses significantes ficam isolados sem enodamento central, sem o enlaçamento fálico. Assim, ordenando certos campos da realidade, esse objeto feito de vários $\mathrm{S}_{1}$ ordenados localiza o gozo do autista como apropriação desse "essaim" que permite o retorno do gozo sobre a borda, como formulou Laurent (1997), testemunhando e opondo-se ao gozo do Outro.

Propondo a renúncia à criança-máquina de Bettelheim, em função da criança-órgão, Laurent (1997) afirma que o objeto da criança é um órgão suplementar, uma lamela, com que a criança tenta introduzir como um órgão que conviria à linguagem em seu corpo. Tal como os objetos que, na civilização, fazem borda com o corpo (sapatos, luvas, casacos ou armaduras), o autista obtém uma interface protetora quando isola o objeto que lhe faz borda e que ele encerra no que pode ser o seu interior mais íntimo. Mais do que um objeto fora-do-corpo, tratar-se-ia no autismo sempre da produção de uma montagem do corpo.

\section{CONCLUSÃO}

Podemos supor, com Zuliani (2008), que a localização da relação do autista com o Outro e com os objetos concretos poderá, talvez, nos fornecer elementos para avançar na discussão sobre o autismo. Entretanto, é preciso salientar, avançaremos desde que consigamos retirar as consequências das referências lacanianas às dimensões do Real, do Simbólico e do Imaginário.

\section{REFERÊNCIAS}

Di Ciaccia, A. (1986). Lacan contra Lacan. In J. Lacan, et al. Il mito indivuduale del nevrotico (pp. 94). Roma: Astrolábio.

Di Ciaccia, A. (2005). A prática entre vários. In S. Altoé \& M. Lima. (Org.). Psicanálise, clínica e Instituição (pp. 34-54.). Rio de Janeiro: Rios Ambiciosos.

Lacan, J. (1962-63). O seminário, livro X: A angústia. Rio de Janeiro: Jorge Zahar, 2005. 
Lacan, J. (1964). O seminário, livro XI: Os quatro conceitos fundamentais da psicanálise. Rio de Janeiro: Jorge Zahar, 1988.

Lacan, J. (1966/1967). Da estrutura como intromistura de uma alteridade, prévia a qualquer que seja o sujeito. In R. Macksey \& E. Donato. (Org.). A controvérsia estruturalista (pp. 260-284). São Paulo: Cultrix.

Lacan, J. ([1967] 1992). Discurso de encerramento das jornadas sobre as psicoses na criança. Boletim da Associação Psicanalítica de Porto Alegre, 3(7), 67-82.

Lacan, J. (1968-1969). O seminário, livro XVI: De um outro ao outro. Rio de Janeiro: Jorge Zahar, 2008.

Lacan,J. (1969-1970). O seminário, livro XVII: O avesso da psicanálise. Rio de Janeiro: Jorge Zahar, 1992.

Lacan, J. (1973-1974). O seminário, livro XX: Mais, ainda. Rio de Janeiro: Jorge Zahar, 1982.

Lacan, J. (1974-1975). O seminário, livro XXII: RSI. Rio de Janeiro: Jorge Zahar.

Lacan, J. (1975/1998). Conferência em Genebra sobre o sintoma. Opção lacaniana, (23), 6-16.

Lacan, J. ([1975]-1976). O seminário, livro XXIII: O sinthoma. Rio de Janeiro: Jorge Zahar, 2007.

Laurent, É. (1991). O gozo do débil. In J. Miller. (Org.). A criança no discurso analítico (pp. 131-135). Rio de Janeiro: Jorge Zahar.

Laurent, É. (1997). Réflexions sur l'autisme, La petite Girafe. Bulletin du Grupe Petite Enfance, (10), 87-94.

Lefort, R., \& Lefort, R. (1984). Nascimento do outro. Salvador: Fator.

Lefort, R., \& Lefort, R. (1997). L'accès de l'enfant à la parole, condition du lien social. L'autisme, Bulletin du Groupe Petite Enfance, (10), 5-12.

Lefort, R., \& Lefort, R. (2003). La distinction de 1'autisme. Paris: Seuil.

Maleval, J-C. (1997). Ébauche d'um aprproche de la spécificité de la psychose autistique, La petite Girafe. Bulletin du Grupe Petite Enfance, (10), 136-138.

Miller,J. (Org.). (1991). A criança no discurso analítico. Rio de Janeiro: Jorge Zahar.
Soler, C. (1997). O sujeito e o outro II. In R. Feldstein, B. Fink \& M. Jaanus. (Org.). Para ler o seminário 11 de Lacan (pp. 58-67). Rio de Janeiro: Jorge Zahar.

Soler, C. ([1997] 2007). Autismo e paranóia. In C. Soler. O inconsciente a céu aberto da psicose (pp. 63-80). Rio de Janeiro: Jorge Zahar.

Vorcaro, A. (1997). A criança na clínica psicanalítica. Rio de Janeiro: Companhia de Freud.

Vorcaro, A. (1999). Da holófrase e seus destinos. In A. Vorcaro. Crianças na psicanálise: Clínica, instituição, laço social (pp. 19-58). Rio de Janeiro: Companhia de Freud.

Vorcaro, A. (2008). A angústia nos autismos e nas psicoses infantis. Reverso, 30(56), 27-30. Recuperado em 20 jan. 2009, em http://scielo.bvs-psi.org.br/pdf/ reverso/v30n56/v30n56a03.pdf

Zuliani, É. (2008). Autisme, automatisme mental et traitemente de l'être. In J. L. Bonnat. (Dir.). Autisme et psychose: Machine autistique et délire machinique, clinique, différentielle des psychoses (pp. 113-122). Rennes: Presses Universitaires de Rennes.

Recebido: 23/03/2009

Received: 03/23/2009

Aprovado: 04/05/2009

Approved: 05/04/2009 